\section{SAT0099 THE RELATIONSHIP OF RHEUMATOLOGY ATTITUDES INDEX WITH OUTCOME MEASURES OF RHEUMATOID ARTHRITIS IN AN ASIAN PATIENT POPULATION}

Jia Zhen Low ${ }^{1}$, Chia Mun Woo ${ }^{2}$, Chien Joo Lim² ${ }^{2}$ Khai Pang Leong ${ }^{3}$, Ee Tzun Koh ${ }^{3} .{ }^{1}$ Ministry of Health Holdings (Singapore), Singapore, Singapore; ${ }^{2}$ Clinical Research and Innovation Office, Tan Tock Seng Hospital Singapore, Singapore, Singapore; ${ }^{3}$ Department of Rheumatology, Allergy and Immunology, Tan Tock Seng Hospital Singapore, Singapore, Singapore

Background: The Rheumatology Attitudes Index (RAl) is a questionnaire comprising of fifteen questions that assesses a patient's beliefs and perception of helplessness and the ability to control rheumatoid arthritis (RA). However, the relationship between RAI and patient demographics, disease activity and functional status is inadequately explored.

Objectives: We analysed the association of RAl with educational level, Physician's Global Assessment of Activity (DGA), Patient's Global Assessment of Activity (PGA), Disease Activity Score (DAS 28), and Health Assessment Questionnaire (HAQ). We also investigated if RAl is sensitive to change over a six-month period in comparison with DGA, PGA, DAS28 and HAQ.

Methods: All patients from Tan Tock Seng Hospital, a tertiary hospital in Singapore, who fulfilled the 1987 ACR criteria for RA, and completed the self-administered RAI questionnaire twice over six months were included. We analysed the DAS28, DGA, PGA and HAQ. Repeated measure ANOVA was used to analyse the association between RAI and educational level. Spearman correlation was used to study the association between RAI and the parameters DAS 28, HAQ, DGA and PGA, both cross-sectionally and longitudinally. We used SPSS version 19.0 (IBM Corp, Armonk, NY). P-value $<0.05$ was considered statistically significant. All the tests were two sided.

Results: There were 501 patients suitable for study. The mean age of disease onset was 43 years and mean disease duration was 15 years. The majority were Chinese (83.4\%), married (68.5\%) and most $(79.4 \%)$ received fewer than 10 years of education. About half $(50.7 \%)$ of the participants suffered from hypertension, $13.6 \%$ diabetes mellitus, $61.5 \%$ hyperlipidaemia, $20.8 \%$ renal disease, $21.6 \%$ liver disease and $16.6 \%$ thyroid disorder. Patients with $<10$ years education have higher RAI scores $(\mathrm{p}<0.001)$ compared to those with $>10$ years of education. Cross-sectionally, weak positive correlation was found between RAI and DAS $28(r=$ 0.225, $p<0.001)$, DGA $(r=0.107, p=0.017)$ and PGA $(r=0.283, p<0.001)$. On the other hand, there was moderate positive correlation between RAI and HAQ $(r=0.440, p<0.001)$. Weak positive correlation was found between the change in RAl compared with changes in DAS $28 \quad(r=$ $0.114, p=0.011), \mathrm{HAQ}(\mathrm{r}=0.249, \mathrm{p}<0.001), \mathrm{DGA}(\mathrm{r}=0.163, \mathrm{p}<0.001)$ and PGA ( $r=0.155, \mathrm{p}=0.001)$.

Conclusion: Higher RAI scores denoting greater perceived helplessness were associated with higher RA activity, HAQ, PGA and DGA. RAI was responsive to change over a six-month period compared with these four parameters. High RAl score was also associated with lower educational level. Higher RAI scores reflects higher disease activity and worse functional status in a cross-sectional cohort and for the same patient longitudinally.

\section{REFERENCE}

[1] Stein MJ, et al. Factor structure of the Arthritis Helplessness Index. J Rheumatol 1988 15(3): 427-32

Disclosure of Interests: None declared

DOI: 10.1136/annrheumdis-2019-eular.3885

\section{SAT0100 IN THE ABSENCE OF GUIDELINES, HOW ARE RHEUMATOLOGISTS MANAGING ANTI-CCP POSITIVE PATIENTS WITHOUT CLINICAL SYNOVITIS?}

Kulveer Mankia ${ }^{1,2}$, Christopher Briggs ${ }^{3}$, Paul Emery ${ }^{1,2}$. ${ }^{1}$ Leeds Institute of Rheumatic and Musculoskeletal Medicine, Rheumatology, Leeds, United Kingdom; ${ }^{2}$ NIHR Leeds Biomedical Research Centre, Leeds, United Kingdom; ${ }^{3}$ Leeds Teaching Hospitals NHS Trust, Rheumatology, Leeds, United Kingdom

Background: The emphasis on early referral and treatment of rheumatoid arthritis (RA) means rheumatologists are now seeing patients earlier in the natural history of RA. Despite clear guidelines for the management of early arthritis, there are no guidelines on how to manage anti-CCP positive $(\mathrm{CCP}+)$ patients with symptoms but no clinical synovitis who are at-risk of developing RA. Given the frequent use of ultrasound (US) in early arthritis clinics, we hypothesised that imaging is being used by rheumatologists to guide the management of these at-risk patients.

Objectives: To survey national practice to identify, in the absence of any guidelines, how $\mathrm{CCP}+$ patients without clinical synovitis are being managed by rheumatologists in the UK and specifically to investigate how imaging is being used to guide management in the 'pre-arthritis' phase of RA.

Methods: Anonymous questionnaires were completed by rheumatologists at a national rheumatology meeting focused on recent advances in rheumatology (Revolutions in Rheumatology 2018, London, UK) and at regional general rheumatology meetings in Yorkshire, UK.

Results: Questionnaires were returned from 47 consultant rheumatologists working in 39 different UK hospitals. 44/47 (94\%) rheumatologists reported they are referred $\mathrm{CCP}+$ patients who have musculoskeletal (MSK) symptoms but no clinical synovitis in their routine clinical practice. Of these, $32 / 44(73 \%)$ were referred $\geq 5$ patients per year. In CCP+ patients with 'inflammatory symptoms' but no clinical synovitis, 36/44 $(82 \%)$ would request an US scan to help guide management and 2/44 (5\%) would request an MRI scan. All respondents would follow these patients regularly and $5 / 44(11 \%)$ would consider a clinical trial. In CCP+ patients with 'non-inflammatory' symptoms and no clinical synovitis, 18/44 $(41 \%)$ would request an US scan, $13 / 44(30 \%)$ would observe in clinic and $12 / 44(27 \%)$ would discharge back to primary care. When specifically asked about use of high-resolution imaging in CCP+ patients without clinical synovitis, 40/44 (91\%) reported they used imaging, with most $(37 / 40$, $93 \%$ ) using US. In patients where power Doppler (PD) signal is present on US in at least one joint, most $(55 \%)$ would start disease-modifying anti-rheumatic drug (DMARD) treatment (figure 1) and 16\% would treat according to RA guidelines. In patients with US tenosynovitis but no US synovitis, most $(73 \%)$ would treat with either corticosteroids alone $(48 \%)$ or a DMARD $(48 \%)$. In contrast, in patients with no US synovitis or US tenosynovitis, 23/37 (62\%) would observe without therapy while 12/37 $(32 \%)$ would discharge the patient (figure 1).

Conclusion: UK rheumatologists are routinely referred CCP+ patients in the pre-arthritis phase of RA and often treat these patients with synthetic DMARDs, guided by US findings. Whether this pragmatic approach is an appropriate one needs to be tested in clinical trials with RA prevention as the ultimate ambition. Guidance on management of these patients would clearly be helpful.

\begin{tabular}{|c|c|c|c|}
\hline \multirow{2}{*}{ Management } & \multicolumn{3}{|c|}{ Ultrasound findings } \\
\cline { 2 - 4 } & $\begin{array}{c}\text { Power Doppler signal } \\
\text { in } \geq 1 \text { joint: } \mathbf{n}(\%)\end{array}$ & $\begin{array}{c}\text { Tenosynovitis only: } \\
\mathrm{n}(\%)\end{array}$ & $\begin{array}{c}\text { No synovitis or } \\
\text { tenosynovitis: } \mathrm{n}(\%)\end{array}$ \\
\hline $\begin{array}{c}\text { Treat according to } \\
\text { RA guidelines }\end{array}$ & $6(16)$ & $0(0)$ & $0(0)$ \\
\hline MTX monotherapy & $8(21)$ & $3(8)$ & $0(0)$ \\
\hline $\begin{array}{c}\text { MTX or HCQ } \\
\text { monotherapy }\end{array}$ & $2(5)$ & $0(0)$ & $0(0)$ \\
\hline HCQ monotherapy & $11(29)$ & $10(27)$ & $2(5)$ \\
\hline $\begin{array}{c}\text { Corticosteroids only } \\
\text { Observe in clinic (no } \\
\text { treatment) }\end{array}$ & $6(16)$ & $13(35)$ & $0(0)$ \\
\hline $\begin{array}{c}\text { Discharge from clinic } \\
\text { (no treatment) }\end{array}$ & $1(3)$ & $8(21)$ & $23(62)$ \\
\hline $\begin{array}{c}\text { Consider for clinical } \\
\text { trial }\end{array}$ & $3(8)$ & $3(8)$ & $12(32)$ \\
\hline
\end{tabular}

Figure 1: The management of anti-CCP positive patients without clinical synovitis accordin to ultrasound findings as reported in a survey of consultant rheumatologists in the UK. RA, rheumatoid arthritis; MTX, methotrexate; HCO, hydroxychloroquine.

Disclosure of Interests: Kulveer Mankia Grant/research support from: Research support from BMS and Lilly, Speakers bureau: Honoraria from Abbvie, UCB, Christopher Briggs: None declared, Paul Emery Grant/ research support from: Pfizer, MSD, AbbVie, Bristol-Myers Squibb, Roche, Consultant for: Pfizer, MSD, AbbVie, Bristol-Myers Squibb, UCB, Roche, Novartis, Gilead,Samsung, Sandoz and Lilly DOI: 10.1136/annrheumdis-2019-eular.6913 